\title{
The Economic Burden of Adults with Major Depressive Disorder in the United States (2010 and 2018)
}

\author{
Paul E. Greenberg ${ }^{1} \cdot$ Andree-Anne Fournier $^{1}$ (D) Tammy Sisitsky $^{1} \cdot$ Mark Simes $^{1} \cdot$ Richard Berman $^{1}$. \\ Sarah H. Koenigsberg ${ }^{1} \cdot$ Ronald C. Kessler ${ }^{2}$
}

Accepted: 11 March 2021 / Published online: 5 May 2021

(c) The Author(s) 2021

\begin{abstract}
Background The incremental economic burden of US adults with major depressive disorder (MDD) was estimated at \$US210.5 billion in 2010 (year 2012 values).

Objective Following a similar methodology, this study updates the previous findings with more recent data to report the economic burden of adults with MDD in 2018.

Method This study used a framework for evaluating the incremental economic burden of adults with MDD in the USA that combined original and literature-based estimates, focusing on key changes between 2010 and 2018. The prevalence rates of MDD by sex, age, employment, and treatment status over time were estimated based on the National Survey on Drug Use and Health (NSDUH). The incremental direct and workplace costs per individual with MDD were primarily derived from administrative claims data and NSDUH data using comparative analyses of individuals with and without MDD. Societal direct and workplace costs were extrapolated by multiplying NSDUH estimates of the number of people with MDD by the direct and workplace cost estimates per patient. The suicide-related costs were estimated using a human capital method. Results The number of US adults with MDD increased by 12.9\%, from 15.5 to 17.5 million, between 2010 and 2018, whereas the proportion of adults with MDD aged 18-34 years increased from 34.6 to $47.5 \%$. Over this period, the incremental economic burden of adults with MDD increased by $37.9 \%$ from $\$$ US236.6 billion to 326.2 billion (year 2020 values). All components of the incremental economic burden increased (i.e., direct costs, suicide-related costs, and workplace costs), with the largest growth observed in workplace costs, at 73.2\%. Consequently, the composition of 2018 costs changed meaningfully, with $35 \%$ attributable to direct costs (47\% in 2010), $4 \%$ to suicide-related costs (5\% in 2010), and $61 \%$ to workplace costs (48\% in 2010). This increase in the workplace cost share was consistent with more favorable employment conditions for those with MDD. Finally, the proportion of total costs attributable to MDD itself as opposed to comorbid conditions remained stable at $37 \%$ (38\% in 2010).

Conclusion Workplace costs accounted for the largest portion of the growing economic burden of MDD as this population trended younger and was increasingly likely to be employed. Although the total number of adults with MDD increased from 2010 to 2018, the incremental direct cost per individual declined. At the same time, the proportion of adults with MDD who received treatment remained stable over the past decade, suggesting that substantial unmet treatment needs remain in this population. Further research is warranted into the availability, composition, and quality of MDD treatment services.
\end{abstract}

Andree-Anne Fournier

Andree-Anne.Fournier@analysisgroup.com

1 Analysis Group, Inc, 111 Huntington Ave., 14th Floor, Boston, MA 02199, USA

2 Harvard Medical School, Boston, MA, USA 


\section{Key Points for Decision Makers}

The economic burden of major depressive disorder (MDD) among US adults increased from \$US236 billion in 2010 to \$US326 billion in 2018 (year 2020 values); the share attributable to workplace costs increased from 48 to $61 \%$ because of more favorable employment conditions for adults with MDD.

Prevalence trends show that younger adults (aged 18-34 years) were increasingly affected by MDD compared with adults aged $\geq 35$ years; adults aged 18-34 years accounted for $47.5 \%$ of the total prevalence in 2018 compared with $36.4 \%$ in 2010 .

Substantial unmet treatment needs remain in the MDD population as the proportion of patients with MDD receiving treatment has not increased from 2010 to 2018.

\section{Introduction}

Major depressive disorder (MDD) remains among the most burdensome disorders worldwide, severely affecting individuals' daily functioning and quality of life and contributing substantially to global disability [1-4]. A recent report by the World Health Organization estimated that MDD affects 322 million people globally, representing an $18.4 \%$ increase in the number of people living with MDD between 2005 and 2015 [4]. MDD is now considered the leading cause of disability worldwide [2].

Not surprisingly, MDD also exacts a heavy personal and economic toll in the USA. The Global Burden of Disease Study found that, of all mental and behavioral health disorders affecting US adults, MDD incurred the heaviest burden, accounting for 2.7 million disability-adjusted life-years in 2016 [5]. Between 2013 and 2016, 8.1\% of US adults aged $\geq 20$ years experienced a depressive episode in a given 2 -week period. Moreover, $80 \%$ of adults with MDD reported difficulty with work and other daily activities as a result of depression [6].

The economic burden of US adults with MDD has risen significantly over time: \$US83.1 billion in 2000 (year 2000 values) [7]; \$US173.2 billion in 2005 (year 2012 values); and \$US210.5 billion in 2010 (year 2012 values) [8]. The 2010 estimate comprised $47 \%$ in direct costs, $5 \%$ in suiciderelated costs, and $48 \%$ in workplace absenteeism and presenteeism [8].

Tracking this rise in the economic burden of US adults with MDD over time can provide useful insights for clinicians and policy makers. In addition, highlighting the societal costs and consequences of the disease from both a healthcare utilization and an employment perspective can inform decisions aimed at improving the lives of those living with MDD. With this in mind, the current study updates our 2010 estimates of the economic burden of MDD, once again focusing on (1) the incremental costs incurred by adults with versus without MDD but with otherwise similar profiles; (2) the incremental costs attributable to MDD itself versus comorbid conditions; and (3) the relative importance of direct costs, suicide-related costs, and workplace costs. We also examined interactions among employment status, treatment status, and disease severity through the business cycle for adults with MDD.

\section{Methods}

The framework used for evaluating the economic burden of adults with MDD drew largely on the approach used in our prior study [8]. The main elements of the methodology, including any key changes, are described in the following sections. A schematic outlining the methodological framework of this study is available in the Electronic Supplementary Material (ESM)-1.

\subsection{Prevalence and Major Depressive Disorder (MDD) Severity Data}

The National Survey on Drug Use and Health (NSDUH), a national probability sample of the US adult civilian, noninstitutionalized population, was used to compare prevalence rates of MDD by sex, age, employment, and treatment status for 2010 and 2018. In the NSDUH depression module, adult respondents were asked questions adapted from the National Comorbidity Survey Replication to assess the rate of individuals with a past-year major depressive episode according to Diagnostic and Statistical Manual of Mental Disorders (DSM)-IV criteria (for respondents in 2010) and DSM-5 criteria (for respondents in 2018) [9-11].

The depression module of the NSDUH also included questions from the Sheehan Disability Scale (SDS) to assess the impairment of individuals with MDD. This self-report tool evaluates functional impairment in the domains of work/school, social life, and family life and measures severe impairment as a maximum score of $\geq 7$ in any SDS domain $[10,12]$.

\subsection{Cost Data: Sample and Control Group}

The OptumHealth Reporting and Insights administrative claims database was used to compare the characteristics and costs of patients with MDD against those without MDD for 
2010 and 2015 (the most recent year for which comprehensive cost and disability data were available). This private, deidentified insurance database was chosen for its robustness and breadth. In particular, it includes comprehensive information regarding patient age, sex, enrollment history, plan type, medical diagnoses, dates and place of service, payment amounts, and pharmacy claims for over 19 million beneficiaries (i.e., employees, spouses, and dependents) from 84 large, self-insured US companies in a broad range of industries with locations in all census areas of the USA [13]. The prior research relied on claims data where diagnoses were recorded based on International Classification of Diseases, Ninth Edition, Clinical Modification (ICD-9-CM) codes, but the current study identified patients with MDD for analysis if they had at least two ICD-9-CM or ICD-10-CM claims for MDD occurring on different dates (ICD-9-CM codes: 296.2, 296.3; ICD-10-CM codes: F32.0-F32.5, F32.9, F33.0-F33.42, F33.9). Patients in each study year were required to have continuous healthcare eligibility. Patients with MDD who had health maintenance organization, capitated, or Medicare coverage were excluded from the analysis because payment information may not have been complete among these groups of patients. To create the control group, patients without any diagnosis of MDD and without any prescription claim for antidepressant, antipsychotic, or antimanic drugs were selected using similar criteria.

To compare characteristics and costs between the two groups, patients with MDD were matched one-to-one with control patients using a combination of direct-characteristic matching (e.g., age, sex, region, insurance type, employment status, relationship to primary beneficiary, and Charlson Comorbidity Index [14-16]) and propensity score analysis. Each patient's propensity score was calculated based on a logistic regression that controlled for general physical comorbidities that were observed to be statistically different at baseline between patients with MDD and control patients but that were not known to be directly related to MDD (e.g., hypertension). Patients with MDD were matched to control patients using a caliper of 0.25 within the standard deviation. Detailed comparisons of characteristics of patients with MDD and control patients before and after patient matching are presented in ESM 2 and 3.

\subsection{Direct Costs Estimation}

Consistent with the prior study, average costs were calculated for both patients with MDD and control patients for three direct cost categories: (1) MDD costs (i.e., medical costs incurred on the same day and in the same location as a medical claim with a diagnosis for MDD, as well as pharmaceutical costs for antidepressant, antipsychotic, and antimanic drugs); (2) other depression costs (i.e., including medical costs incurred on the same day and in the same location as a medical claim with a diagnosis for another type of depression (e.g., bipolar depression) but not MDD specifically, as well as pharmaceutical costs for antianxiety and anticonvulsant drugs); and (3) nondepression costs (i.e., all medical and pharmaceutical costs not captured in either of the first two categories). Incremental costs of patients with MDD were calculated by subtracting average costs of matched controls from those of patients with MDD (ESM 4 presents the detailed calculations for employed and treated adults with MDD in 2010 and 2015). The first cost category was the basis for estimating the direct costs of MDD, whereas all three categories combined were used to estimate the direct costs of individuals with MDD.

Employment and MDD treatment status were accounted for in the estimation of direct costs per patients with MDD: (1) for employed and treated patients, costs were estimated using the claims data; (2) for employed and not treated patients, MDD costs were set equal to 0 and non-MDD costs (comprising other depression costs and nondepression costs) were set equal to those incurred by employed and treated patients; and (3) for nonemployed patients (either treated or not treated), costs were assumed to be 1.7 times those found in the employed population, an assumption based on the ratio of healthcare costs incurred by patients with MDD with Medicaid coverage compared with patients with MDD who were privately insured [17]. (ESM 5 presents detailed calculations of ratios used to infer otherwise missing cost categories.) Because the claims data did not contain cost information for patients aged $\geq 65$ years, costs for these patients were assumed to be equal to those observed in patients aged 50-64 years.

Societal direct costs were extrapolated by multiplying NSDUH estimates of the number of people with MDD by the direct cost estimates per patient for each of the three cost categories noted above, stratified by age and sex. Because the NSDUH data did not contain the exact age for all respondents, the age stratifications in our study relied upon age categories available in the NSDUH (i.e., ages 18-25, $26-34,35-49$, and $\geq 50$ years). These categories are consistent with those used in our prior study, allowing for direct age-related prevalence comparisons.

\subsection{Suicide-Related Costs Estimation}

Suicide-related costs for 2010 and 2018 were estimated using the human capital method, stratified by age and sex. The total number of suicides for each year was obtained from the Centers for Disease Control [18]. Based on prior literature, our study attributed $50 \%$ of suicides to MDD in our cost estimates [19-21]. The present value of lifetime earnings was estimated using mortality rates and life expectancies from the National Vital Statistics Report as well as earnings data from the National Bureau of Economic 
Research [22-24]. A 3\% discount rate was applied to the mortality cost estimates to express future earnings in present value terms [25]. (ESM 6 presents the number of suicides and estimated loss of lifetime earnings due to MDD in 2010 and 2018.)

\subsection{Workplace Costs Estimation}

Workplace costs incurred by individuals with MDD included attention to both absenteeism due to missed days of work and presenteeism due to reduced productivity while at work. These costs were estimated for the same three categories as described for direct costs (i.e., MDD costs, other depression costs, and nondepression costs). Three different categories of absenteeism costs were considered: (1) injury/illness, (2) discretionary time off, and (3) disability. For absenteeism due to illness or injury, time away from work was imputed for the employed and treated subgroup based on the claims data: outpatient visits on workdays were counted as a halfday of missed work, and inpatient or emergency department visits on workdays were counted as full days missed. Discretionary time off was estimated based on NSDUH data in which respondents reported the number of workdays missed "because the respondent didn't want to be there". Costs of absenteeism associated with these first two categories were estimated by multiplying the cumulative number of days absent from work, from both categories, by that employee's daily wage, which was included in the claims data. Costs of absenteeism associated with the third category, disability, were assessed directly from the claims data for the employed and treated subgroup. Absenteeism costs for individuals who were employed but not treated were assumed to be $44 \%$ of the costs incurred by those in the employed and treated group based on the ratio of workdays missed reported by each group in the NSDUH. Presenteeism costs were assumed to be 6.1 times the costs of absenteeism due to illness or injury based on previous literature estimates [26]. (ESM 5 presents detailed calculations of ratios used to infer otherwise missing cost categories.) Societal workplace costs were extrapolated using the approach described for estimating total direct costs.

\subsection{Statistical Analyses}

For the analyses of NSDUH data, $p$ values for the changes across years in prevalence, employment, and treatment status were calculated using a two-sample $z$ test for independent proportions. In the analyses of the OptumHealth claims data, statistical tests were performed using chi-squared tests for categorical variables and $t$ tests for continuous variables.

Because our study relied on a combination of original estimates and estimates based on previously published literature, we performed sensitivity analyses for all estimates that incorporated literature-based estimates. Key parameters derived from the literature were increased and decreased by $10 \%$ to determine the extent to which the outcomes would change in either direction.

Analyses of the NSDUH and OptumHealth claims data, including propensity score matching, were performed using SAS Enterprise Guide version 7.15 (SAS Institute Inc., Cary, NC, USA). Costs were adjusted to \$US, year 2020 values, using the medical care index of the Consumer Price Index.

\section{Results}

\subsection{Prevalence, Severity, Employment and Treatment Rates}

Between 2010 and 2018, the total number of US adults with MDD increased by $12.9 \%$, from 15.5 to 17.5 million. This change was driven by the $7.7 \%$ growth in the US adult population from 228.5 million to 246.0 million as well as the rise in the prevalence rate of MDD from 6.8 to $7.1 \%$ (Table 1A).

The increase in the number of MDD cases was unevenly distributed by age, with a $53.7 \%$ increase among adults aged 18-34 years, from 5.4 million to 8.3 million. Although this age group accounted for $34.6 \%$ of all adults with MDD in 2010 , it rose to $47.5 \%$ of total prevalence in 2018 . At the same time, the number of MDD cases among adults aged $\geq 35$ years declined by $9.8 \%$ over this period, from 10.2 to 9.2 million (Fig. 1).

The reported number of severely impaired adults with MDD rose from 9.6 million in 2010 or $61.8 \%$ of those with MDD, to 11.3 million in 2018 or $64.6 \%$ of those with MDD (data not shown). In addition, approximately one-third of adults with MDD reported being severely impaired in the work domain, a proportion that remained relatively stable between 2010 and 2018, corresponding to 5.3 million people in 2010 and 5.6 million people in 2018 (data not shown).

Improving macroeconomic conditions between 2010 and 2018 drew more individuals with MDD into the workforce. Following the sharp economic downturn in 2008, the proportion of adults with MDD who were employed either full or part time was $55.3 \%$ in 2010 and rose to $59.9 \%$ in 2018 following an extended economic expansion. Conversely, the proportion of adults with MDD who were not employed decreased from 44.7 to $40.1 \%$ during this period (Table 1A). Even as these business cycle dynamics benefited individuals with MDD by drawing more of them into the workforce, they imposed added direct and workplace costs on employers. The long-term employment trends for individuals with and without MDD are presented in Fig. 2.

Although the treatment rate among adults with MDD remained stable, 1.0 million more people were treated for MDD in 2018 than in 2010 (9.7 vs. 8.7 million) (Table 1B). 
Table 1 Prevalence, employment, and treatment rates of MDD

\begin{tabular}{|c|c|c|c|c|c|c|c|c|c|}
\hline \multicolumn{10}{|c|}{ A. Prevalence of adults with MDD in past year by employment status ${ }^{\mathrm{a}}$} \\
\hline \multirow[t]{2}{*}{$\overline{\text { Status }}$} & \multicolumn{3}{|l|}{$2010^{\mathrm{b}}$} & \multicolumn{4}{|l|}{2018} & \multicolumn{2}{|c|}{ Change $(2010-2018)^{\mathrm{c}}$} \\
\hline & All adults & $\begin{array}{l}\text { Adults with } \\
\text { MDD }\end{array}$ & $\begin{array}{l}\text { Prevalence } \\
\text { rate }(\%)\end{array}$ & All adults & \multicolumn{2}{|c|}{$\begin{array}{l}\text { Adults with } \\
\text { MDD }\end{array}$} & $\begin{array}{l}\text { Prevalence } \\
\text { rate }(\%)\end{array}$ & Adults with MDD & $\begin{array}{l}\text { Prevalence } \\
\text { rate }(\%)\end{array}$ \\
\hline Employed full-time & $114,023,964$ & $6,274,910$ & 5.5 & $122,542,772$ & \multicolumn{2}{|c|}{$7,696,432$} & 6.3 & $1,421,523$ & 0.8 \\
\hline Employed part-time & $33,056,026$ & $2,312,373$ & 7.0 & $31,859,894$ & \multicolumn{2}{|c|}{$2,798,607$} & 8.8 & 486,233 & 1.8 \\
\hline Not employed & $81,438,556$ & $6,946,896$ & 8.5 & $91,634,491$ & \multicolumn{2}{|c|}{$7,018,244$} & 7.7 & 71,348 & -0.9 \\
\hline Total & $228,518,546$ & $15,534,179$ & 6.8 & $246,037,157$ & \multicolumn{2}{|c|}{$17,513,283$} & 7.1 & $1,979,104$ & 0.3 \\
\hline \multicolumn{10}{|c|}{ B. Treatment rate of adults with MDD in past year by employment status ${ }^{\mathrm{a}, \mathrm{d}}$} \\
\hline & \multicolumn{3}{|l|}{2010} & \multicolumn{4}{|l|}{2018} & \multicolumn{2}{|l|}{ Change (2010-2018) } \\
\hline & \multicolumn{2}{|c|}{ No. of treated cases } & Rate $(\%)$ & \multicolumn{2}{|c|}{ No. of treated cases } & \multicolumn{2}{|c|}{ Rate $(\%)$} & No. of treated cases & $\begin{array}{l}\text { Change in } \\
\text { rate }(\%)\end{array}$ \\
\hline Employed full-time & \multicolumn{2}{|c|}{$3,225,244$} & 51.5 & $4,158,136$ & \multicolumn{3}{|c|}{54.0} & 932,892 & 2.5 \\
\hline Employed part-time & \multicolumn{2}{|c|}{$1,136,974$} & 49.3 & $1,441,642$ & \multicolumn{3}{|c|}{51.7} & 304,668 & 2.4 \\
\hline Not employed & \multicolumn{2}{|c|}{$4,329,892$} & 62.3 & $4,120,908$ & \multicolumn{3}{|c|}{58.8} & $-208,984$ & -3.5 \\
\hline Total & \multicolumn{2}{|c|}{$8,692,110$} & 56.0 & $9,720,686$ & \multicolumn{3}{|c|}{55.6} & $1,028,576$ & -0.5 \\
\hline
\end{tabular}

$M D D$ major depressive disorder, NSDUH National Survey on Drug Use and Health

Data source: US Department of Health and Human Services. National Survey on Drug Use and Health, public-use files, 2010 and 2018 [11]

an 2010 and 2018, MDD in past year is based on the variable AMDDEYR (“Adult: past year major depressive episode”). In 2010, employment status is based on the variable EMPSTAT4 ("Imputation revised employment status 18+"). In 2018, employment status is based on the variable IRWRKSTAT ("Employment status_imputation revised"). Results are weighted based on the variable ANALWT_C ("Final person-level sample weight") for 2018 and on the variable AWTC10_C ("2010 analysis weight poststratified to 2010 census totals") for 2010. Adults with unknown MDD status were excluded from analysis

${ }^{b}$ Values for 2010 varied slightly from previously published results because of ongoing revisions of the NSDUH data. Values for 2010 varied further because of the use of an updated weighting variable relative to previously published results. None of the study conclusions were impacted by the variations

${ }^{c} p<0.001$ for all changes. $p$ values for the change across years are calculated using the two-sample $z$ test for independent proportions

dTreatment rate was identified based on the variable AMHTXRC3 ("Received any mental health treatment in past year")

Adults with severe impairment due to MDD were more likely to be treated than those without severe impairment (data not shown). The highest treatment rate was found among patients with MDD who were not employed, whereas the lowest was associated with part-time employment (Table 1B).

\subsection{MDD Costs: 2010 vs. 2018}

The incremental economic burden of adults with MDD rose from \$US236.6 billion in 2010 to \$US326.2 billion in 2018 (year 2020 values), representing an increase of $37.9 \%$ over this 8-year period (Table 2A; ESM 7 compares the incremental economic burden of adults with MDD in 2018 and the previously published 2005 and 2010 summary results, all expressed in year 2012 values). The composition of overall costs changed meaningfully in 2018 , with $35 \%$ attributable to the direct costs of treatment (47\% in 2010), $4 \%$ attributable to suicide-related costs (5\% in 2010), and $61 \%$ to indirect workplace costs (48\% in 2010). In contrast, the portion of the incremental costs attributable to MDD as opposed to comorbid conditions remained quite stable in 2018 at $37 \%$ (38\% in 2010) (Table 2B, C).

\subsubsection{Direct Costs}

In 2018, direct costs incurred by individuals with MDD rose to \$US114.3 billion from \$US111.1 billion in 2010, an increase of $2.8 \%$ (Table 2A). This was the result of a $12.9 \%$ growth in the number of MDD cases (Table 1A) combined with a 9.3\% decline in the average cost per MDD case (Table 3 ). The decline in cost per case was driven, in part, by a sizable reduction in the incremental cost of prescription drugs, particularly with regard to antidepressant medications that were increasingly available at relatively low cost due to the effects of generic competition (data not shown). Pharmacy expenditure accounted for \$US20.4 billion in 2018 (6\% of direct costs), a sizable decrease from \$US31.6 billion in 2010 (13\% of direct costs) (Table 2A). As was the case with results from 2010, the largest component of direct costs of treating patients with 

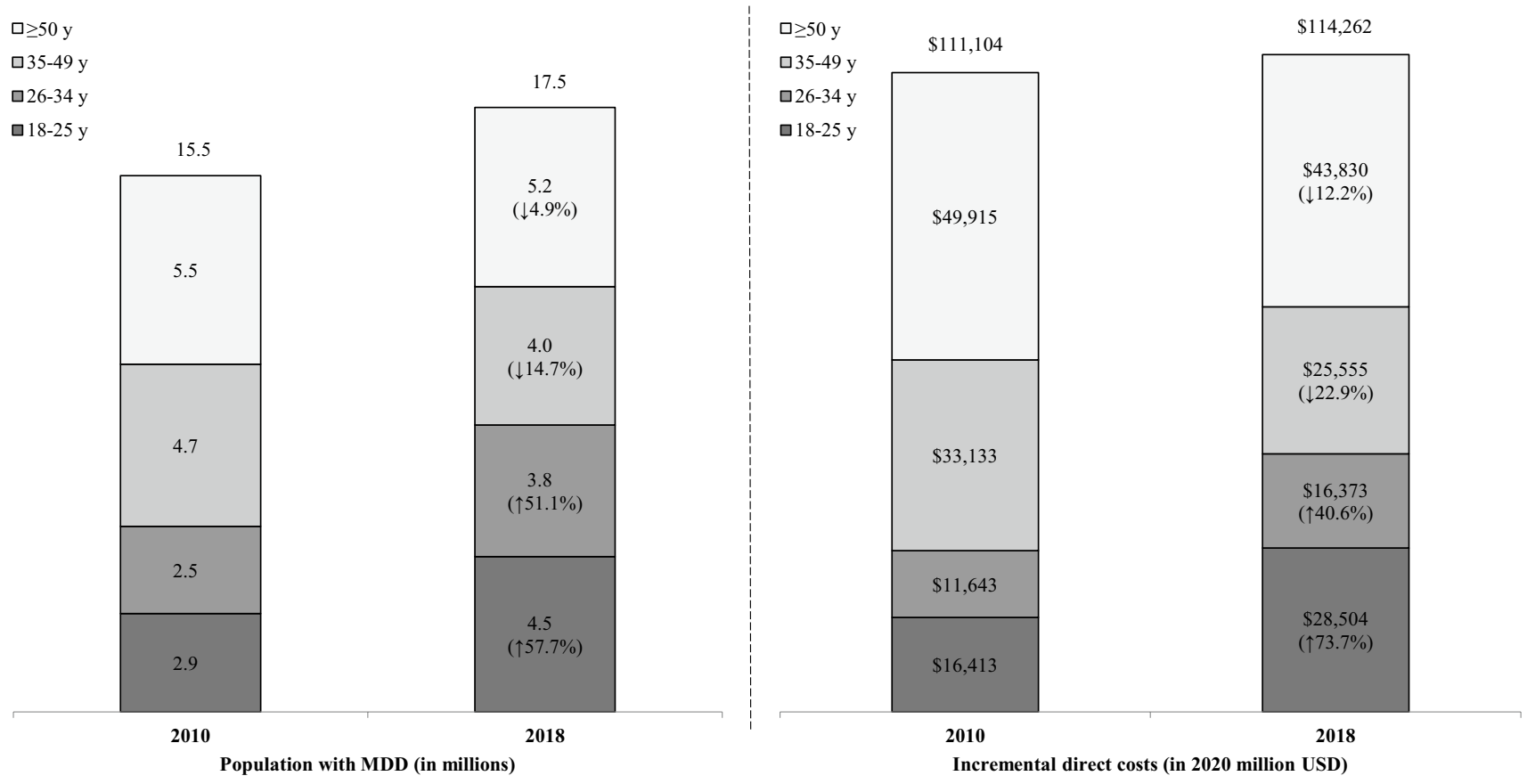

Fig. 1 Prevalence and costs of individuals with MDD by age group (\$US, year 2020 values). $M D D$ major depressive disorder

MDD in 2018 remained the costs of outpatient and inpatient services. Adults with MDD aged 18-25 and 26-34 years had very large increases in total incremental direct costs (i.e., 73.7 and $40.6 \%$, respectively). In contrast, costs associated with adults aged $\geq 35$ years decreased by $16.5 \%$ between 2010 and 2018 (Fig. 1).

\subsubsection{Suicide-Related Costs}

In total, 46,510 adult suicides occurred in 2018 [18] and, consistent with the earlier study, $50 \%$ were attributed to MDD [8]. The $25 \%$ rise in suicides from 2010 resulted in a $22.8 \%$ increase in suicide costs, from \$US10.9 billion in 2010 to \$US13.4 billion in 2018 (Table 2A; ESM 6 presents the detailed calculations of lifetime earnings lost due to MDD in 2010 and 2018).

\subsubsection{Workplace Costs}

Workplace costs continued to represent the largest component of the burden of adults with MDD (61\%). This cost category increased by $73 \%$ from \$US114.6 billion in 2010 to \$US198.6 billion in 2018. Presenteeism accounted for $70 \%$ of workplace costs (up 57\%), whereas absenteeism accounted for the remaining 30\% (up 129\%) (Table 2A).

\section{Discussion}

The primary objective of this study was to update the year 2010 estimates of the economic burden of adults with MDD based on similar methodology using year 2018 data. This update included attention to (1) the incremental costs incurred by adults with MDD compared with those of adults without MDD but with otherwise similar profiles; (2) the portion of these costs attributable to MDD itself as well as comorbid conditions; and (3) the relative importance of the different components of the economic burden of adults with MDD, including direct costs, suicide-related costs, and workplace costs. An additional objective was to assess the dynamics among employment status, treatment status, and disease severity through the business cycle for adults with MDD. 
Employed full time

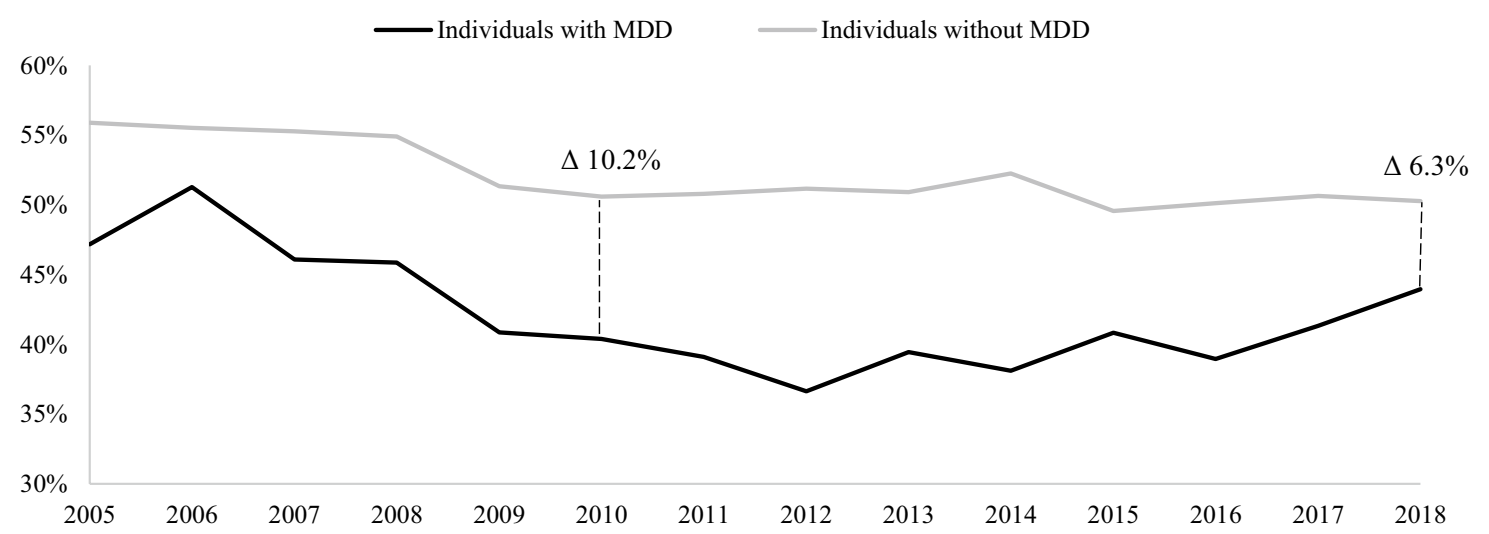

Employed part time

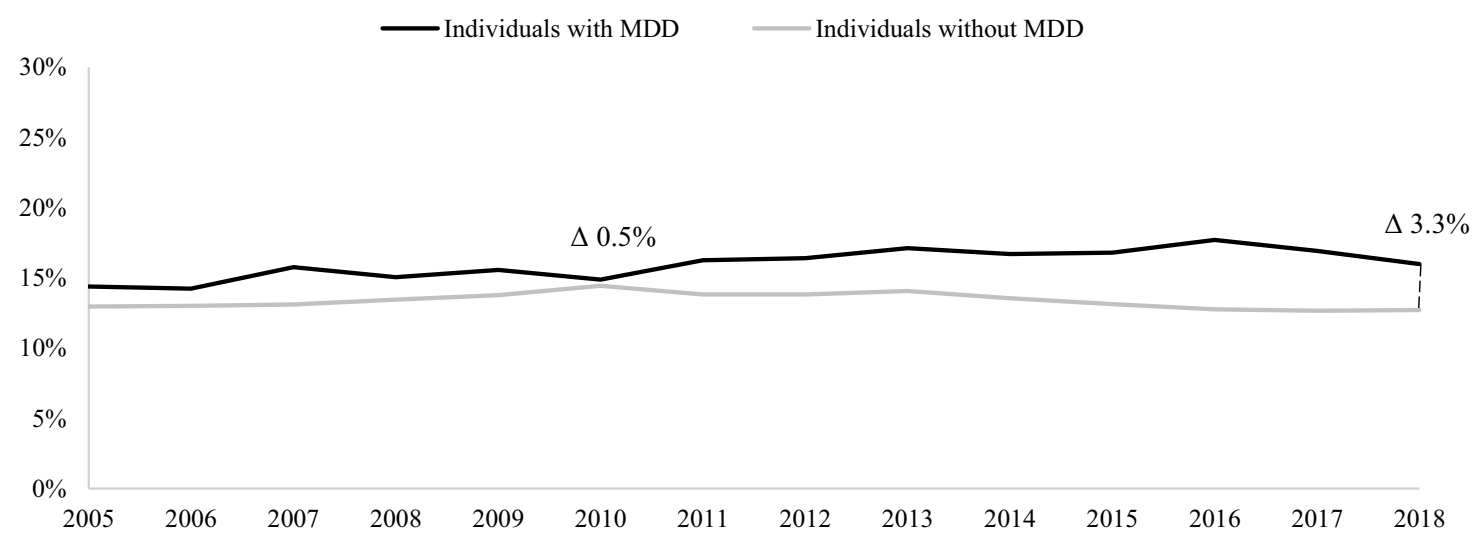

Not employed

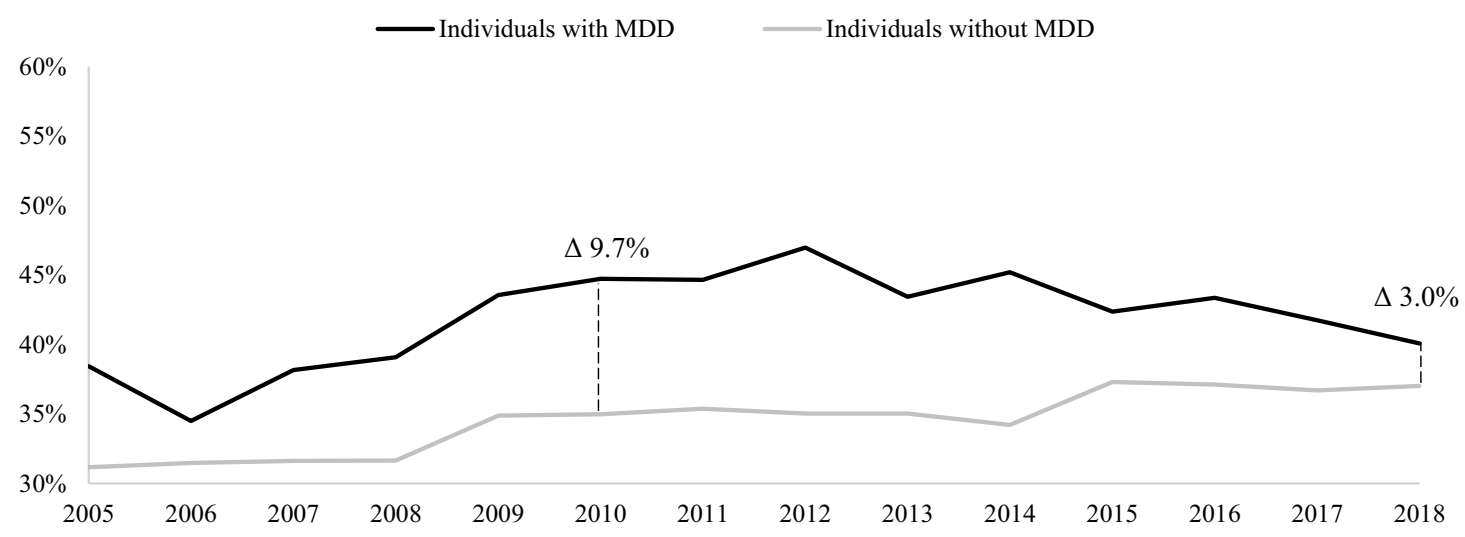

Fig. 2 Employment status of individuals with and without MDD, 2005-2018. MDD major depressive disorder

\subsection{Economic Burden of Adults with MDD}

The current study shows that adults with MDD impose a sizable annual economic burden on society of \$US326.2 billion, an increase of $37.9 \%$ relative to 2010 (Table $2 \mathrm{~A}$ ). Approximately $40 \%$ of this rise is attributable to an increase in the number of individuals with MDD, and the remaining $60 \%$ is the result of increased costs per person 
Table 2 Incremental economic burden of adults with MDD in 2010 and 2018 (all costs and costs of MDD alone, \$US, year 2020 values)

\begin{tabular}{|c|c|c|c|c|c|}
\hline \multirow[t]{2}{*}{ Type of cost } & \multicolumn{2}{|l|}{2010} & \multicolumn{2}{|l|}{2018} & \multirow{2}{*}{$\begin{array}{l}2010-2018 \\
\text { Change in dollars } \\
(\%)\end{array}$} \\
\hline & Dollars (millions) & Percent of total & Dollars (millions) & Percent of total & \\
\hline \multicolumn{6}{|c|}{ A. Incremental economic burden of adults with MDD } \\
\hline Direct costs & 111,104 & 47 & 114,262 & 35 & 2.8 \\
\hline Medical services & 79,502 & 34 & 93,888 & 29 & 18.1 \\
\hline Outpatient & 42,940 & 18 & 49,428 & 15 & 15.1 \\
\hline Inpatient & 23,150 & 10 & 27,605 & 8 & 19.2 \\
\hline ER & 5545 & 2 & 11,349 & 3 & 104.7 \\
\hline Other medical services & 7867 & 3 & 5506 & 2 & -30.0 \\
\hline Pharmaceutical services & 31,602 & 13 & 20,374 & 6 & -35.5 \\
\hline Suicide-related costs & 10,892 & 5 & 13,373 & 4 & 22.8 \\
\hline Workplace costs & 114,643 & 48 & 198,596 & 61 & 73.2 \\
\hline Absenteeism & 26,222 & 11 & 60,035 & 18 & 129.0 \\
\hline Presenteeism & 88,421 & 37 & 138,561 & 42 & 56.7 \\
\hline Total & 236,638 & 100 & 326,231 & 100 & 37.9 \\
\hline \multicolumn{6}{|c|}{ B. Incremental economic burden attributable to MDD } \\
\hline Direct costs & 31,119 & 34 & 36,628 & 30 & 17.7 \\
\hline Medical services & 18,710 & 21 & 28,943 & 24 & 54.7 \\
\hline Outpatient & 11,348 & 13 & 15,862 & 13 & 39.8 \\
\hline Inpatient & 5482 & 6 & 10,809 & 9 & 97.2 \\
\hline ER & 180 & 0 & 1293 & 1 & 616.8 \\
\hline Other medical services & 1699 & 2 & 979 & 1 & -42.4 \\
\hline Pharmaceutical services & 12,409 & 14 & 7686 & 6 & -38.1 \\
\hline Suicide-related costs & 10,892 & 12 & 13,373 & 11 & 22.8 \\
\hline Workplace costs & 48,325 & 53 & 70,783 & 59 & 46.5 \\
\hline Absenteeism & 10,411 & 12 & 20,085 & 17 & 92.9 \\
\hline Presenteeism & 37,915 & 42 & 50,697 & 42 & 33.7 \\
\hline Total & 90,337 & 100 & 120,784 & 100 & 33.7 \\
\hline \multicolumn{6}{|c|}{ C. Incremental economic burden attributable to comorbid conditions } \\
\hline Direct costs & 79,984 & 55 & 77,634 & 38 & -2.9 \\
\hline Medical services & 60,792 & 42 & 64,946 & 32 & 6.8 \\
\hline Outpatient & 31,591 & 22 & 33,567 & 16 & 6.3 \\
\hline Inpatient & 17,668 & 12 & 16,796 & 8 & -4.9 \\
\hline ER & 5365 & 4 & 10,056 & 5 & 87.4 \\
\hline Other medical services & 6168 & 4 & 4527 & 2 & -26.6 \\
\hline Pharmaceutical services & 19,192 & 13 & 12,688 & 6 & -33.9 \\
\hline Workplace costs & 66,317 & 45 & 127,813 & 62 & 92.7 \\
\hline Absenteeism & 15,811 & 11 & 39,949 & 19 & 152.7 \\
\hline Presenteeism & 50,506 & 35 & 87,863 & 43 & 74.0 \\
\hline Total & 146,302 & 100 & 205,447 & 100 & 40.4 \\
\hline
\end{tabular}

$E R$ emergency room, $M D D$ major depressive disorder

${ }^{\mathrm{a}}$ Panel A represents the sum of panels B and C

with MDD, especially those borne in the workplace (data not shown).

It is striking that the direct cost of treating MDD itself accounted for only $11.2 \%$ of the overall economic burden. In fact, for every dollar spent on MDD direct costs, an additional \$US2.30 was spent on MDD-related indirect costs (i.e., MDD-related workplace costs, suicide-related costs), and another \$US5.61 was spent on direct and indirect comorbidity costs (Fig. 3). These results are in line with recent literature demonstrating that integrative and collaborative care should continue to be favored to lower the economic burden of adults with MDD [27-29]. 
Table 3 Incremental direct cost per case of individuals with MDD by employment status, treatment status, and age group, 2010 and 2018

\begin{tabular}{cccc}
\hline & \multicolumn{2}{c}{$\begin{array}{l}\text { Annual cost per case (\$US, year 2020 } \\
\text { values) }\end{array}$} \\
\cline { 2 - 4 } & 2010 & 2018 & Change $(\%)$ \\
\hline Employed & 5081 & 4890 & -3.8 \\
Treated & 6427 & 6197 & -3.6 \\
$18-25$ & 6369 & 6907 & 8.4 \\
$26-34$ & 4728 & 4646 & -1.7 \\
$35-49$ & 6710 & 6010 & -10.4 \\
$\geq 50$ & 7557 & 7161 & -5.2 \\
Not treated & 3671 & 3393 & -7.6 \\
$18-25$ & 3455 & 3942 & 14.1 \\
$26-34$ & 2508 & 2450 & -2.3 \\
$35-49$ & 3850 & 3404 & -11.6 \\
$\geq 50$ & 4705 & 3847 & -18.2 \\
Not employed & 9807 & 8968 & -8.6 \\
Treated & 11,693 & 11,000 & -5.9 \\
$18-25$ & 10,697 & 11,708 & 9.5 \\
$26-34$ & 8009 & 7764 & -3.1 \\
$35-49$ & 11,173 & 10,229 & -8.4 \\
$\geq 50$ & 12,897 & 12,288 & -4.7 \\
Not treated & 6669 & 6065 & -9.1 \\
$18-25$ & 5798 & 6697 & 15.5 \\
$26-34$ & 4324 & 3981 & -7.9 \\
$35-49$ & 6740 & 5758 & -14.6 \\
$\geq 50$ & 7859 & 6599 & -16.0 \\
Total & 7193 & 6524 & -9.3 \\
\hline
\end{tabular}

$M D D$ major depressive disorder

Whereas patients aged 18-34 years accounted for $34.6 \%$ of the MDD population in 2010, this age group accounted for $47.5 \%$ of the MDD population in 2018 (Fig. 1), driven by an increasing prevalence rate in this age group (data not shown). Direct costs increased sharply for this group (Fig. 1), driven by both an increase in the number of individuals with MDD and growth in direct costs per individual (Table 3). These results suggest that further research is warranted concerning the drivers of the direct costs within the younger age cohorts as well as strategies to ameliorate those drivers.

In addition to the change in age distribution over time, the proportion of adults with MDD who were employed full or part time increased by 4.6 percentage points between 2010 and 2018 (Table 1A). This increase in the number of employed adults with MDD, combined with a rising incremental absenteeism and presenteeism cost per individual with MDD, contributed to a significant increase in the workplace costs of MDD between 2010 and 2018. Whereas workplace costs accounted for $48 \%$ of the burden of adults with
MDD in the prior study, they made up $61 \%$ of the total costs in 2018 (Table 2A). With an increasing number of adults with MDD in the workforce, including younger adults in particular, identifying ways to reduce workplace costs could translate into significant reductions in the economic burden of MDD from the perspective of employers and society. Effectively treating MDD could reduce the economic burden in the workplace by reducing presenteeism and absenteeism [30].

The current study also adds to our understanding of the relationship between MDD and the business cycle in showing that economic fluctuations are often experienced more profoundly by people with MDD than those without. The economic downturn of 2008 disproportionately affected the MDD population, and its adverse impacts lasted longer than those in the non-MDD population. In addition, the improvements in the labor market between 2010 and 2018 were reflected in a closing of the gaps in both full-time employment and unemployment between individuals with MDD and those without (Fig. 2). Even so, the proportion of adults with MDD who were not employed remained higher than that of individuals without MDD (Table 1A). These dynamics point to the importance of further research on the relationship between the economics of MDD through the business cycle and the resulting burden imposed on patients, providers, employers, and society.

Among adults with MDD for whom the disease is more severe, the consequences of business cycle fluctuations are even more pronounced. Looking back to the 2008 downturn, individuals with MDD who self-reported severe impairment in the workplace had experienced a decline of 12.1 percentage points in their full-time employment rate, from $35.6 \%$ in 2005 to $23.5 \%$ in 2010 (data not shown). By 2018, this rate had grown to $31.7 \%$ but was still well below the $47.7 \%$ full-time employment rate of people with MDD who did not report severe impairment in any domains (i.e., work/school, social life, or family life) (data not shown).

Whereas severely impaired people with MDD were more likely to be treated than those without severe impairment (61.2 vs. $45.4 \%)$ in 2018 , treatment rates among the severely impaired did not increase over the past decade (data not shown). One possible explanation for the stagnation in treatment rates is that considerable stigma remains associated with mental illness [31]. However, on a positive note, a recent poll by the American Psychiatric Association found that younger workers (millennials) are nearly twice as likely to feel comfortable discussing their mental health in the workplace than are the "baby boomer" generation [32]. As such, this younger population may be more receptive to targeted treatment interventions. Accordingly, innovations such as smartphone apps that are designed to reach the young adult working population, might be effective in reducing the economic burden of illness [33-37]. More 
Fig. 3 Additional costs of individuals with MDD for every dollar spent on MDD direct costs in 2018. ER emergency room, $M D D$ major depressive disorder

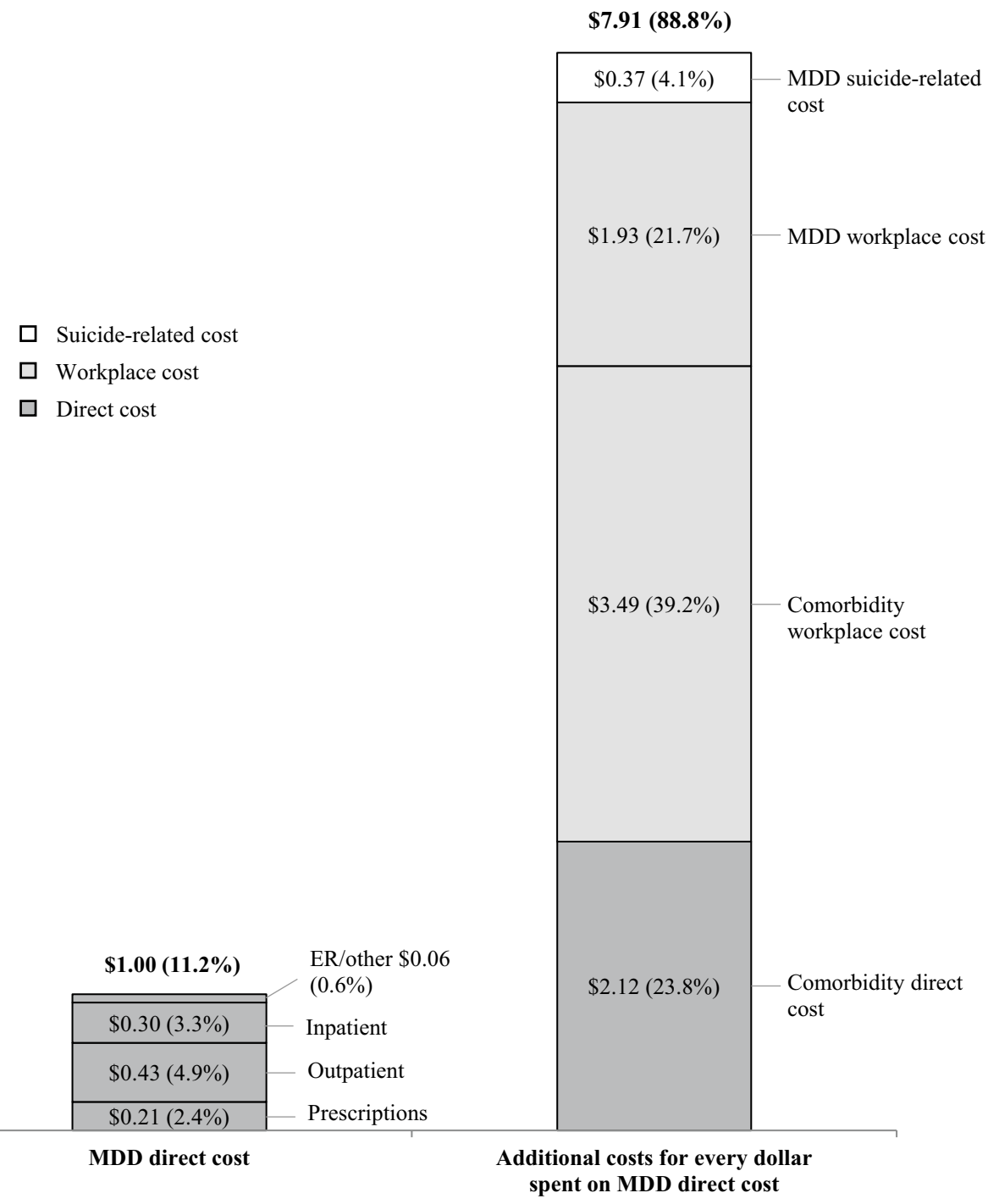

generally, new types of pharmaceutical therapies, as well as new interventional approaches that rely on the power of data science innovations in making customized treatment recommendations to each patient, may help increase the percentage of individuals with MDD who are successfully treated.

Although the treatment rate of MDD remained stable between 2010 and 2018 at approximately $56 \%$, the employment status of individuals with MDD who received treatment changed substantially. Among individuals who were treated for MDD, there was an increase over this time period of 1.2 million who were employed and a reduction of 0.2 million who were not employed (Table 1B). One recent systematic review found that workplace interventions are an effective way to provide increased access to treatment, resulting in positive immediate and short-term outcomes [38]. To the extent there is continued progress resulting in further increases in the treatment rate among employed adults, it will be useful to assess the extent to which such improvements are associated with overall reductions in the economic burden analyzed here.

The complex interactions among MDD severity, employment, and treatment merit further study to better understand the drivers of the outcomes observed in our study. Moreover, researchers have already begun to probe the effects of the coronavirus disease 2019 (COVID-19) pandemic on mental health in the USA and globally [39-41]. In addition to the overall economic contraction caused by the pandemic, the widespread shift to remote work for many adults may influence the balance between the costs of absenteeism and presenteeism in the workplace. Future research examining the experience of adults with MDD in the labor market should consider the effects of the pandemic on these factors. 


\subsection{Limitations}

The limitations to this study, which we summarize briefly here, are broadly the same as those highlighted in the prior study [8]. First, in the absence of a single data source to evaluate the economic burden of adults with MDD, our approach continues to rely on a combination of original and literature-based estimates. As in the prior study, we performed a sensitivity analysis with respect to the key parameters drawn from estimates in the literature (ESM 5). We found that increasing (or decreasing) these parameters by $10 \%$ resulted in an increase (or decrease) in the costs of adults with MDD of 5\% and in the costs of MDD of $6 \%$. Second, we continued to estimate presenteeism based on the relationship between presenteeism and absenteeism costs in 2002 while mindful that this relationship might have evolved over time with changes in the demographics of the MDD population in the workplace or structural changes in the nature of work (e.g., during and following the pandemic). Third, the NSDUH data do not contain the exact age for all respondents. As such, our study relied on the age groupings available in the data. Furthermore, our claims data do not allow for direct estimation of costs for individuals aged $\geq 65$ years. Consistent with the prior study, we continued to impute these costs based on the cost estimates for those aged 50-64 years. Fourth, our data do not allow for analysis of beneficiaries covered under certain types of managed care plans, leading to the possibility that our extrapolation did not fully reflect the experiences of these individuals. Fifth, potentially important cost categories were not incorporated into the methodology, thereby resulting in understated estimates. This included the effects of MDD on students and their career/ life paths, caregiver burdens, and quality-of-life reductions for individuals with MDD and their families. Finally, use of claims data in the current study relied on 2015 results for a 2018 burden-of-illness estimate. To the extent MDD treatment costs rose during this period, the estimates presented here would understate the true totals.

\section{Conclusion}

The economic burden of adults with MDD continued to rise over time, with workplace costs growing disproportionately. Although direct costs per patient declined, the number of adults with MDD increased and trended younger. Improvements in macroeconomic conditions since 2010 translated into more favorable employment rates for the MDD population but also resulted in increased absenteeism and presenteeism costs in the workplace. At the same time, the proportion of adults with MDD who received treatment did not increase over the past decade, suggesting that substantial unmet treatment needs remain in this population. Finally, direct costs per treated individual declined and societal costs of MDD increased, suggesting that further research is warranted into the availability, composition, and quality of optimal MDD treatment services to address continued unmet need.

Supplementary Information The online version contains supplementary material available at https://doi.org/10.1007/s40273-021-01019-4.

Acknowledgements The authors are grateful for the research assistance provided by Nathaniel Downes, BA; Leigh Franke, MA; Schuyler Livingston, MBA; and Travis Wang, MS, of Analysis Group, Inc.

\section{Declarations}

Funding No sources of funding were used to conduct this study or prepare this manuscript.

Conflict of interest In the past 3 years, Dr. Kessler has served as a consultant for DataStat, Inc., Sage Pharmaceuticals, and Takeda. Messrs. Greenberg, Simes, and Berman and Mss. Fournier, Sisitsky, and Koenigsberg are employees of Analysis Group, Inc., which provides consulting services to a range of biopharma companies.

Availability of data and material Not applicable.

Ethics approval Not applicable.

Consent Not applicable.

Author contributions PG, A-AF, TS, MS, and RK contributed to the study conception and design. MS, RB, and SK performed data collection, preparation, and analyses. A-AF and MS wrote the first draft of the manuscript, and all authors commented on previous versions of the manuscript. All authors read and approved the final manuscript.

Open Access This article is licensed under a Creative Commons Attribution-NonCommercial 4.0 International License, which permits any non-commercial use, sharing, adaptation, distribution and reproduction in any medium or format, as long as you give appropriate credit to the original author(s) and the source, provide a link to the Creative Commons licence, and indicate if changes were made. The images or other third party material in this article are included in the article's Creative Commons licence, unless indicated otherwise in a credit line to the material. If material is not included in the article's Creative Commons licence and your intended use is not permitted by statutory regulation or exceeds the permitted use, you will need to obtain permission directly from the copyright holder. To view a copy of this licence, visit http://creativecommons.org/licenses/by-nc/4.0/.

\section{References}

1. WHO Depression Fact Sheet. World Health Organization (WHO). 2020. https://www.who.int/news-room/fact-sheets/detail/depre ssion. Accessed 3 Dec 2020. 
2. Friedrich MJ. Depression is the leading cause of disability around the world. JAMA. 2017;317(15):1517. https://doi.org/10.1001/ jama.2017.3826.

3. Liu Q, He H, Yang J, Feng X, Zhao F, Lyu J. Changes in the global burden of depression from 1990 to 2017: findings from the Global Burden of Disease Study. J Psychiatr Res. 2020;126:134-40. https://doi.org/10.1016/j.jpsychires.2019.08.002.

4. Depression and Other Common Mental Disorders: Global Health Estimates. World Health Organization (WHO). 2017. https://apps. who.int/iris/bitstream/handle/10665/254610/WHO-MSD-MER2017.2-eng.pdf. Accessed 3 Dec 2020.

5. The US Burden of Disease Collaborators. The State of US Health, 1990-2016: burden of diseases, injuries, and risk factors among US States. JAMA. 2018;319(14):1444-72. https://doi.org/10. 1001/jama.2018.0158.

6. Brody DJ, Pratt LA, Hughes J. Prevalence of depression among adults aged 20 and over: United States, 2013-2016. National Center for Health Statistics. 2018; Data Brief, no 303.

7. Greenberg PE, Kessler RC, Birnbaum HG, Leong SA, Lowe SW, Berglund PA, et al. The economic burden of depression in the United States: how did it change between 1990 and 2000? J Clin Psychiatry. 2003;64(12):1465-75. https://doi.org/10.4088/jcp. v64n1211.

8. Greenberg PE, Fournier AA, Sisitsky T, Pike CT, Kessler RC. The economic burden of adults with major depressive disorder in the United States (2005 and 2010). J Clin Psychiatry. 2015;76(2):15562. https://doi.org/10.4088/JCP.14m09298.

9. National Survey on Drug Use and Health. U.S. Department of Health and Human Services, Substance Abuse and Mental Health Services Administration, Center for Behavioral Health Statistics and Quality, Rockville, MD. 2019. https://www.datafiles.samhsa. gov/study-series/national-survey-drug-use-and-health-nsduhnid13517. Accessed 03 Dec 2020.

10. National Survey on Drug Use and Health Public Use File Codebooks 2005-2018. U.S. Department of Health and Human Services, Substance Abuse and Mental Health Services Administration, Center for Behavioral Health Statistics and Quality, Rockville, MD. 2019. https://www.datafiles.samhsa.gov/studyseries/national-survey-drug-use-and-health-nsduh-nid13517. Accessed 03 Dec 2020.

11. National Survey on Drug Use and Health 2005-2018 (NSDUH2005-DS0001-NSDUH-2018-DS0001). U.S. Department of Health and Human Services, Substance Abuse and Mental Health Services Administration, Center for Behavioral Health Statistics and Quality, Rockville, MD. 2019. https://datafiles.samhsa.gov/. Accessed 03 Dec 2020.

12. Leon AC, Olfson M, Portera L, Farber L, Sheehan DV. Assessing psychiatric impairment in primary care with the Sheehan Disability Scale. IJPM. 1997;27(2):93-105. https://doi.org/10.2190/ T8EM-C8YH-373N-1UWD.

13. OptumHealth Care Solutions, Inc. 2017. https://www.optum.com/ business/solutions/data-analytics/data/real-world-data-analytics-a$\mathrm{cpl} /$ claims-data.html.

14. Charlson ME, Pompei P, Ales KL, MacKenzie CR. A new method of classifying prognostic comorbidity in longitudinal studies: development and validation. J Chronic Dis. 1987;40(5):373-83. https://doi.org/10.1016/0021-9681(87)90171-8.

15. Quan H, Sundararajan V, Halfon P, Fong A, Burnand B, Luthi JC, et al. Coding algorithms for defining comorbidities in ICD-9-CM and ICD-10 administrative data. Med Care. 2005;43(11):1130-9. https://doi.org/10.1097/01.mlr.0000182534.19832.83.

16. Quan H, Li B, Couris CM, Fushimi K, Graham P, Hider P, et al. Updating and validating the Charlson comorbidity index and score for risk adjustment in hospital discharge abstracts using data from 6 countries. Am J Epidemiol. 2011;173(6):676-82. https://doi.org/ 10.1093/aje/kwq433.
17. Ivanova JI, Birnbaum HG, Chen L, Duhig AM, Dayoub EJ, Kantor ES, et al. Cost of post-traumatic stress disorder vs major depressive disorder among patients covered by Medicaid or private insurance. Am J Manag Care. 2011;17(8):e314-23.

18. National Center for Injury Prevention and Control, WISQARS Fatal Injury Reports. Centers for Disease Control and Prevention. 2018. http://www.cdc.gov/injury/wisqars/index.html. Accessed 03 Dec 2020.

19. Blumenthal SJ, Kupfer DJ. Suicide Over the Life Cycle: Risk Factors, Assessment, and Treatment of Suicidal Patients. American Psychiatric Pub. 1990.

20. Nock MK, Kessler RC. Prevalence and risk factors for suicide attempts versus suicide gestures: analysis of the National Comorbidity Survey. J Abnorm Psychol. 2006;115(3):616-23.

21. Karch DL, Barker L, Strine TW. Race/ethnicity, substance abuse, and mental illness among suicide victims in 13 US states: 2004 data from the National Violent Death Reporting System. Injury Prev. 2006. https://doi.org/10.1136/ip.2006.013557.

22. Kochanek KD, Murphy SL, Xu J, Arias E. Deaths: Final Data for 2017. National Vital Statistics Reports. 2019;68(9).

23. Murphy SL, Xu J, Kochanek KD. National Vital Statistics Reports Deaths: Preliminary Data for 2010. 2012;60(4).

24. Research NBoE. National Bureau of Economic Research MORG 18 Data. 2018. https://data.nber.org/morg/annual. Accessed 03 Dec 2020.

25. Max W, Rice D, Sung H-Y, Michel M. Valuing Human Life: Estimating the Present Value of Lifetime Earnings, 2000. Center for Tobacco Control Research and Education, UC San Francisco, University of California at San Francisco, Center for Tobacco Control Research and Education. 2004.

26. Stewart WF, Ricci JA, Chee E, Hahn SR, Morganstein D. Cost of lost productive work time among US workers with depression. JAMA. 2003;289(23):3135-44. https://doi.org/10.1001/jama.289. 23.3135

27. Archer J, Bower P, Gilbody S, Lovell K, Richards D, Gask L, et al. Collaborative care for depression and anxiety problems. Cochrane Database Syst Rev. 2012. https://doi.org/10.1002/14651 858.CD006525.pub2.

28. Simon GE, Katon WJ, VonKorff M, Unützer J, Lin EH, Walker EA, et al. Cost-effectiveness of a collaborative care program for primary care patients with persistent depression. Am J Psychiatry. 2001;158(10):1638-44. https://doi.org/10.1176/appi.ajp.158.10. 1638.

29. Katon W, Russo J, Lin EHB, Schmittdiel J, Ciechanowski P, Ludman E, et al. Cost-effectiveness of a multicondition collaborative care intervention: a randomized controlled trial. Arch Gen Psychiatry. 2012;69(5):506-14. https://doi.org/10.1001/archgenpsy chiatry.2011.1548.

30. Chisholm D, Sweeny K, Sheehan P, Rasmussen B, Smit F, Cuijpers $P$, et al. Scaling-up treatment of depression and anxiety: a global return on investment analysis. Lancet Psychiatry. 2016;3(5):415-24. https://doi.org/10.1016/S2215-0366(16) 30024-4.

31. Clay J, Eaton J, Gronholm PC, Semrau M, Votruba N. Core components of mental health stigma reduction interventions in lowand middle-income countries: a systematic review. Epidemiol Psychiatr Sci. 2020;29:e164. https://doi.org/10.1017/s204579602 0000797.

32. American Psychiatric Association. About half of workers are concerned about discussing mental health issues in the workplace; a third worry about consequences if they seek help. American Psychiatric Association. 2019. https://www.psychiatry.org/newsr oom/news-releases/about-half-of-workers-are-concerned-aboutdiscussing-mental-health-issues-in-the-workplace-a-third-worryabout-consequences-if-they-seek-help. Accessed 03 Dec 2020. 
33. Arean PA, Hallgren KA, Jordan JT, Gazzaley A, Atkins DC, Heagerty PJ, et al. The use and effectiveness of mobile apps for depression: results from a fully remote clinical trial. J Med Internet Res. 2016;18(12):e330. https://doi.org/10.2196/jmir.6482.

34. Bakker D, Kazantzis N, Rickwood D, Rickard N. A randomized controlled trial of three smartphone apps for enhancing public mental health. Behav Res Ther. 2018;109:75-83. https://doi.org/ 10.1016/j.brat.2018.08.003.

35. Graham AK, Greene CJ, Kwasny MJ, Kaiser SM, Lieponis P, Powell $\mathrm{T}$, et al. Coached mobile app platform for the treatment of depression and anxiety among primary care patients: a randomized clinical trial. JAMA Psychiat. 2020;77(9):906-14. https:// doi.org/10.1001/jamapsychiatry.2020.1011.

36. McCloud T, Jones R, Lewis G, Bell V, Tsakanikos E. Effectiveness of a mobile app intervention for anxiety and depression symptoms in university students: randomized controlled trial. JMIR mHealth uHealth. 2020;8(7):e15418. https://doi.org/10. 2196/15418.

37. Firth J, Torous J, Nicholas J, Carney R, Pratap A, Rosenbaum S, et al. The efficacy of smartphone-based mental health interventions for depressive symptoms: a meta-analysis of randomized controlled trials. World Psychiatry. 2017. https://doi.org/10.1002/ wps.20472.

38. Wan MYWMA, Musiat P, Brown JSL. Systematic review of universal and targeted workplace interventions for depression. Occup Environ Med. 2018;75(1):66-75. https://doi.org/10.1136/ oemed-2017-104532.

39. Panchal N, Kamal R, Cox C, Garfield R. The Implications of COVID-19 for Mental Health and Substance Abuse. Kaiser Family Foundation. 2021. https://www.kff.org/coronavirus-covid-19/ issue-brief/the-implications-of-covid-19-for-mental-health-andsubstance-use/. Accessed 12 Feb 2021.

40. Ettman CK, Abdalla SM, Cohen GH, Sampson L, Vivier PM, Galea S. Prevalence of depression symptoms in US adults before and during the COVID-19 pandemic. JAMA Netw Open. 2020;3(9):e2019686. https://doi.org/10.1001/jamanetworkopen. 2020.19686.

41. Torales J, O'Higgins M, Castaldelli-Maia JM, Ventriglio A. The outbreak of COVID-19 coronavirus and its impact on global mental health. Int J Soc Psychiatry. 2020;66(4):317-20. https://doi. org/10.1177/0020764020915212. 